\title{
Processing and Material Characteristics of a Reclaimed Ground Rubber Tire Reinforced Styrene Butadiene Rubber
}

\author{
Debapriya De $^{1^{*}}$, Debasish $\mathrm{De}^{2}$ \\ ${ }^{1}$ Chemistry Department, MCKV Institute of Engineering, Liluah, India; ${ }^{2}$ Chemistry Department, Meghnad Saha Institute of Tech- \\ nology, Kolkata, India. \\ Email: debapriyad2001@yahoo.com
}

Received January $21^{\text {st }}, 2011$; revised May $6^{\text {th }}, 2011$; accepted May $12^{\text {th }}, 2011$.

\begin{abstract}
Mechanochemically partially devulcanized ground rubber tire (GRT) was revulcanized in composition with virgin styrene butadiene rubber (SBR). Reclaiming of GRT was carried out by tetra methyl thiuram disulfide (TMTD) in presence of spindle oil. The cure characteristics and tensile properties of SBR compounds were investigated. Results indicate that the minimum torque and Mooney viscosity of the SBR compounds increase with increasing reclaim rubber (RR) loading whereas the scorch time remain unaltered but optimum cure time exhibit a decreasing trend. Increasing RR loading also gives SBR compounds better resistance towards swelling but the 100\% modulus, $200 \%$ modulus tensile strength, and the elongation at break increases. Thermogravimetric analysis of SBR/RR vulcanizates was carried out in order to get thermal stability of the vulcanizates. Scanning electron microscopy (SEM) studies further indicate the coherency and homogeneity in the SBR/RR vulcanizates.
\end{abstract}

Keywords: Rubber Recycling, SBR, TMTD, Reclaimed Rubber, Thermogravimetric Analysis, Crosslink Density

\section{Introduction}

Dwindling source and rising price of crude oil have become a serious concern for availability of feed stock to the synthetic rubber industry. Huge quantities of rubbers are used in tire industry and the world's rubber markets are dominated by two rubbers - one being natural rubber (NR) and the other being styrene butadiene rubber (SBR). Among different rubbers, tire industry consumed largest quantity of SBR which is mainly used in car tire tread. But after a long run when these tires are not serviceable only a few grams or kilograms of rubber are abraded out from the tire. The entire amount of rubber from the worn-out tires is discarded, which again require very long time for environmental degradation due to cross- link structure of rubbers. Various approaches such as land filling [1], incineration [2], pyrolysis [3,4], civil engineering $[5,6]$ applications etc. have been adopted for reuse of waste discarded rubber products. But in almost all the applications no value is added from the product side.

Tire recycling or reclaiming are one of the preferable routes, according to the so-called waste management hierarchy, under environmental aspect. The recycling of tires not only saves our valuable resource of petroleum from which the synthetic rubbers are originated, but also protects our precious environment. Thus reclaiming of tires in alternative applications is actually the use of base polymer in new formulations with simultaneous cost saving in raw material and preserving both natural resource and environment. Incorporation and dispersion of reclaim rubber in fresh rubber play important roles towards the product quality, production economy and market competition. Compatibility of reclaim rubber with virgin rubber is an essential requirement for optimum mechanical properties of the vulcanizates. Therefore it is necessary to evaluate the performances of such fresh rubber/reclaim rubber blends.

In a review paper the author [7] have discussed the various reclaiming processes of vulcanized rubber in presence of different chemicals. The mechanical reclaiming of GRT by TMTD as reclaiming agent was studied by the author [8]. Here the extent of reclaiming was monitored by measurement of sol content, inherent viscosity of sol rubber, crosslink density and Mooney vis- 
cosity of reclaim rubber as function of milling time and concentration of reclaiming agent. The optimization of the reclaiming agent concentration and time of reclaiming was also reported. The performance evaluations of such type of reclaim rubber/virgin natural rubber blend was also studied [9] by the author. In this paper mechanochemically partially devulcanized GRT was blended with fresh NR in $20 \%-60 \%$ level. The reclaim rubber, prepared in this investigation, when blended with fresh NR has been found to reduce the tensile strength by about $7 \%$ for $20 \%$ reclaim containing vulcanizate and $46 \%$ for $60 \%$ reclaim containing vulcanizate. It is observed that the aging performances of the reclaim rubber containing vulcanizates are better than the control formulation, which does not contain any reclaim rubber. TGA shows that the thermal stability of the vulcanizate increases with increasing reclaim rubber content. Noordermeer et al. [10] reclaimed waste latex rubber by diphenyl disulfide, 2-aminopheny disulfide and 2, 2'-dibenzamidodiphenyl disulfide as a function of concentration of reclaiming agent, time and temperature. The comparative study of the reclaiming efficiency of the three reclaiming agents was carried out. From the study it was evident that 2, 2'-dibenzamidodiphenyl disulfide is able to break the crosslink bonds at around $20^{\circ} \mathrm{C}$. Sombatsompop and Kumnuantrip [11,12] incorporated reclaim rubber from tire tread into two grades of NR and investigated various properties of the blend. They found that Mooney number, shear viscosity and cure rate increased with RR content but optimum cure time is independent of it. Sreeja and Kutty [13] studied the cure characteristics and mechanical properties of NR/RR blends, using the EV system. They reported that scorch time and tensile properties of the blend reduced with RR loading. The curing characteristics and mechanical properties of SBR/RR blend system was reported by the author [14]. Here reclaiming of waste rubber was carried by a simple process with an eco-friendly renewable resource material $[15,16]$. The main constituent of this material is diallyl disulfide. Other constituents are disulfides, mono sulfides, poly sulfides and thiol compounds. Nevatia et al. [17] mixed RR with recycled poly ethylene and evaluated physical properties, dynamic mechanical properties and rheological behaviors of the blend. They reported that $50 / 50, \mathrm{RR} / \mathrm{PE}$ vulcanizate showed optimum processibility, ultimate elongation and set properties. Here sulfur-accelerator cured system gave superior product properties than peroxide cured system.

This paper describes a new elastomer products based on virgin SBR and reclaimed GRT. Initial step involves the mechanochemical reclaiming of GRT by TMTD and subsequent incorporation of reclaimed GRT into virgin SBR in different proportion. The (re)vulcanization of different SBR/RR blends was found to give a new low cost product with adequate properties. The term (re)vulcanization was used because there are two simultaneous processes such as vulcanization of the virgin rubber and (re)vulcanization of partially devulcanized GRT and even the co-vulcanization of them. Curing characteristics and mechanical properties before and after aging of SBR/RR blend system have been studied. Thermal behavior of RR, SBR and different SBR/RR vulcanizates was also studied. Finally the dispersion of reclaim rubber into SBR was evaluated by scanning electron microscopy (SEM).

\section{Experimental}

\subsection{Materials}

GRT, purchased from local market was used in this investigation. The GRT was an unclassified ground rubber from the tread and side walls of passenger and truck tires. The particles of GRT were of various sizes ranging from a few millimeters to 100 microns. Styrene butadiene rubber (SBR 1502, Synthetics \& Chemicals Ltd. India), tetramethylthiuram disulfide (TMTD) (Alpha Chemika, Maharashtra, India), zinc oxide (S. D. Fine Chem. India), stearic acid (Loba Chemi. India), sulfur (S. D. Fine Chem. India), spindle oil (MCI, India), carbon black (N330, Philips Carbon Ltd. India) and toluene (S. D. Fine Chem. India) were used as received.

\subsection{Experimental Procedure}

The optimization of reaction conditions and the concentration of TMTD used for reclaiming of GRT were reported in the author's previous work [8]. Hundred grams of ground rubber was thoroughly mixed with $2.75 \mathrm{~g}$ TMTD and $10 \mathrm{~mL}$ spindle oil. The mixture was then reclaimed mechanically in an open two-roll mixing mill at a friction ratio of 1.2 for 40 minutes near ambient temperature. It has been found that with progress of milling the materials become soft, sticky and band formation occurs on the roll. The extent of reclaiming was monitored by measurement of sol content $(30.3 \%)$, inherent viscosity of sol rubber (0.3944), crosslink density $(6.587$ $\left.\times 10^{-4} \mathrm{~mol} / \mathrm{cm}^{3}\right)$, molecular weight between crosslink bonds $\left(33.093 \times 10^{3}\right)$, swelling ratio (4.099) and Mooney viscosity [ML $(1+4) 100^{\circ} \mathrm{C}$ ] (70.6) of reclaim rubber [8].

\subsection{Preparation of SBR/RR Vulcanizates}

Mixing of fresh SBR, various proportions of reclaim rubber and compounding ingredients was carried out for 15 minutes at room temperature on an open two-roll mixing mill. Compound formulations are presented in Table 1. The amount of additives such as $\mathrm{ZnO}$, stearic 
Table 1. Mix formulation and curing characteristics of SBR/RR Compounds.

\begin{tabular}{|c|c|c|c|c|c|c|c|c|c|c|}
\hline Ingredients (phr) & 1 & 2 & 3 & 4 & 5 & 6 & 7 & 8 & 9 & 10 \\
\hline Styrene Butadiene rubber (SBR) & 100 & 80 & 70 & 60 & 50 & 40 & 100 & 80 & 80 & 80 \\
\hline Reclaim rubber (RR) & - & 20 & 30 & 40 & 50 & 60 & - & 20 & 20 & 20 \\
\hline Zinc oxide & 5 & 5 & 5 & 5 & 5 & 5 & 5 & 5 & 5 & 5 \\
\hline Stearic acid & 2 & 2 & 2 & 2 & 2 & 2 & 2 & 2 & 2 & 2 \\
\hline TMTD & 2.16 & 1.61 & 1.335 & 1.06 & 0.785 & 0.51 & 2.16 & 1.61 & 1.61 & 1.61 \\
\hline Sulfur & 0.5 & 0.5 & 0.5 & 0.5 & 0.5 & 0.5 & 0.5 & 0.5 & 0.5 & 0.5 \\
\hline carbon Black (N330) & - & - & - & - & - & - & 40 & 20 & 30 & 40 \\
\hline Spindle oil & - & - & - & - & - & - & 4 & 2 & 3 & 4 \\
\hline \multicolumn{11}{|l|}{ Curing Characteristics } \\
\hline Optimum cure time $\left(\mathrm{t}_{90}, \mathrm{~min}\right)$ & 7.5 & 5.5 & 5.25 & 4.75 & 4.5 & 4.25 & 10 & 5.25 & 6.0 & 4.5 \\
\hline Scorch time $\left(t_{\mathrm{s} 2}, \min \right)$ & 1.5 & 0.5 & 1.0 & 1.0 & 1.0 & 1.0 & 0.5 & 0.5 & 0.5 & 0.5 \\
\hline Extent of cure, $(\mathrm{dNm})$ & 49 & 54.2 & 55.5 & 55.6 & 56 & 58 & 68.5 & 58 & 63 & 68 \\
\hline Cure rate index, $\left(\min ^{-1}\right)$ & 16.7 & 20 & 23.5 & 26.7 & 28.6 & 30.8 & 10.5 & 21 & 18.2 & 25 \\
\hline \multicolumn{11}{|l|}{ Mechanical Properties } \\
\hline $100 \%$ Modulus, MPa & 1.255 & 1.59 & 1.62 & 2.10 & 2.13 & 2.28 & 3.5 & 2.146 & 3.267 & 4.196 \\
\hline $200 \%$ Modulus, MPa & 1.698 & 2.25 & 2.31 & 3.08 & 3.19 & 3.32 & 5.477 & 3.264 & 4.985 & 6.465 \\
\hline Tensile Strength, MPa & 2.335 & 2.781 & 2.974 & 3.835 & 4.573 & 5.017 & 12.014 & 7.515 & 9.946 & 12.577 \\
\hline$\%$ Elongation at break & 432 & 377 & 382 & 390 & 427 & 445 & 537 & 587 & 521 & 509 \\
\hline Hardness, (Shore A) & 50 & 60 & 65 & 64 & 62 & 60 & 65 & 60 & 63 & 65 \\
\hline Crosslinking value, (1/Q) & 0.238 & 0.292 & 0.324 & 0.358 & 0.376 & 0.406 & 0.300 & 0.300 & 0.325 & 0.337 \\
\hline Mooney Viscosity [ML $\left.(1+4) 100^{\circ} \mathrm{C}\right]$ & 40.7 & 51.0 & 65.7 & 70.6 & 71.8 & 75.0 & - & - & - & - \\
\hline
\end{tabular}

acid and sulfur were used based on $100 \mathrm{~g}$ of rubber irrespective of the amount of reclaim rubber, because it was reported that the additives in reclaim rubber originated from parent compound are inactive [18]. The amount of TMTD was maintained at $9 \mathrm{~m} \mathrm{~mol}$ in all the vulcanizates based on the amount of TMTD used during reclaiming of GRT. This is due to the fact that in sulfur, TMTD vulcanization system the optimum concentration of TMTD is chosen as $9 \mathrm{~m}$ mol i.e. $2.16 \mathrm{~g}$ per hundred gm of fresh rubber (i.e. RR and SBR). Formulation 1 contains no reclaim rubber and formulation 2 - 6 contains different proportion of reclaim rubber from $20-60 \mathrm{wt} \%$. In order to study the effect of carbon black, various proportion of carbon black was added in SBR/RR (80/20) blend system. Formulation 7 contains only SBR with 40 phr carbon black and formulation $8-10$ contain different 
proportion of carbon black (20,30 and $40 \mathrm{phr})$ in SBR/RR blend. It has been observed that with increase in the proportion of carbon black its incorporation and dispersion become gradually difficult. With higher proportion of carbon black loading the compounds become stiff and the temperature rises due to high shearing action required for better dispersion.

The cure characteristics of SBR/RR compounds were determined with the help of a Monsanto Oscillating Disc Rheometer, R-100 at $160^{\circ} \mathrm{C}$. It has been found that all cure curves were level off in the region of 60 minutes, where torque-time gradient of each sample was constant or did not change significantly.

The compounded rubber stock were then cured in a compression molding machine at $160^{\circ} \mathrm{C}$ and at applied pressure of $34.5 \mathrm{MPa}$ for the respective optimum cure time $\left(t=t_{90}\right)$ obtained from rheographs. After curing, the vulcanized sheet was taken out of the mold and immediately cooled under tap to restrict from further curing.

\subsection{Measurement of Mechanical Properties}

The mechanical properties such as modulus, tensile strength and elongation at break was measured by a Hounsfield, model H10 KS tensile testing machine as per ASTM D 412-51T at room temperature $\left(25 \pm 2^{\circ} \mathrm{C}\right)$ at a uniform speed of separation $500 \mathrm{~mm} / \mathrm{min}$. Hardness (Shore A) of the vulcanizates were measured by a Hirosima Hardness tester as per ASTM D 1415-56T. The values reported were based on the average of five measurement of each sample. The aging characteristics of the vulcanizates was evaluated by accelerated aging test in an air aging oven at $100 \pm 2^{\circ} \mathrm{C}$ after 24,48 and $72 \mathrm{~h}$ aging.

Mooney viscosities of rubber compounds were determined by a Monsanto Mooney viscometer 2000 at ML (1 +4) $100^{\circ} \mathrm{C}$ as per ASTM D 1646.

\subsection{Swelling Value of the Vulcanizates}

The swelling value $(Q)$ was determined with about $0.5 \mathrm{~g}$ of cured samples (accurately weighed). The sample was immersed in $250 \mathrm{~mL}$ toluene for $72 \mathrm{~h}$ to attain equilibrium swelling. After equilibrium swelling the sample was taken out and the solvent was blotted from the surface of the sample and weighed immediately. It was then dried under vacuum at $100^{\circ} \mathrm{C}$ upto constant weight. The crosslinking value of the vulacanizates was calculated from the following equation [19].

$$
\frac{1}{Q}=\frac{W_{S}-W_{D}}{\left(\frac{W_{0} \times 100}{W_{F}}\right)}
$$

where $W_{S}, W_{D}, W_{O}$ and $W_{F}$ are swollen weight, dried weight, weight of the original sample and formula weight respectively. Formula weight $\left(W_{F}\right)$ is the total weight of rubber plus compounding ingredients based on 100 parts of rubber.

\subsection{Determination of Crosslink Density}

The crosslink densities of SBR/RR vulcanizates were determined by the Flory-Rehner equation [20] by using swelling value measurement.

$$
-\ln \left(1-V_{r}\right)-V_{r}-\chi V_{r}^{2}=2 V_{s} \eta_{\text {swell }}\left(V_{r}^{\frac{1}{3}}-\frac{2 V_{r}}{f}\right)
$$

where $V_{r}$ is the volume fraction of rubber in the swollen gel, $V_{S}$ is the molar volume of the toluene $\left(106.2 \mathrm{~cm}^{3} \cdot \mathrm{mol}^{-1}\right.$ in this study), $\chi$ is the rubber-solvent interaction parameter ( 0.378 in this study), $\eta_{\text {swell }}$ is cross-link density of the rubber $\left(\mathrm{mol} \cdot \mathrm{cm}^{-3}\right)$ and $f$ is functionality of the crosslinks (being 4 for sulphur curing system).

The volume fraction of a rubber network in the swollen phase is calculated from equilibrium swelling data as:

$$
V_{r}=\frac{\left(\frac{W_{2}}{d_{2}}\right)}{\left(\frac{W_{1}}{d_{1}}\right)+\left(\frac{W_{2}}{d_{2}}\right)}
$$

where $W_{1}$ is the weight fraction of solvent, $d_{1}$ is the density of the solvent, $W_{2}$ is the weight fraction of the polymer in the swollen specimen and $d_{2}$ is the density of the polymer.

\subsection{Thermo Gravimetric Analysis (TGA)}

The thermo gravimetric analysis (TGA) of SBR/RR vulcanizate was carried out by using a TGA 50, Shimadzu, Japan, thermo-gravimetric analyzer in nitrogen (flow rate $50 \mathrm{~mL} / \mathrm{min}$ ) within the temperature range of 20 to $800^{\circ} \mathrm{C}$. All these analysis were carried out at heating rate of $10^{\circ} \mathrm{C} / \mathrm{min}$.

\subsection{Scanning Electron Microscopy}

The tensile fracture surface of the samples were studied in scanning electron microscope (SEM) (JEOL, JSM $5800)$ at $0^{\circ}$ tilt angle after coating the surface with sputtered gold.

\section{Results and Discussion}

\subsection{Curing Characteristics}

Curing characteristics of different SBR/RR blend system and SBR/RR (80/20) blend system with various proportions of carbon black loading are given in Table 1. The optimum cure time decreases but scorch time remain unaltered with increase in reclaim rubber content in all 
the cases. From Table 1 it has been found that with increase in the proportion of reclaim rubber extent of cure increases due to the presence of crosslinked gel in the reclaim rubber. It is also evident that with increase in carbon black loading the optimum cure time and scorch time remain unaffected but extent of cure increases with increasing carbon black loading.

\subsection{Tensile Properties of Rubber Compound}

The stress-strain behavior of SBR/RR vulcanizates with various proportion of reclaim rubber are shown in Figure 1. The moduli at $100 \%$ and $200 \%$ elongation increases with increasing reclaim rubber content in all the SBR/RR vulcanizates. The stress strain was decreased with increasing reclaim rubber content. From the Figure it is shown that the stress-strain of SBR/RR vulcanizates was decreased after $50 \%$ elongation compare to that of the fresh SBR vulcanizate. Tensile properties, Mooney viscosity and crosslinking value of the SBR/RR vulcanizates are presented in Table 1. From the values in Table 1 it is seen that moduli at $100 \%$ and $200 \%$ elongation, tensile strength, elongation at break and hardness increases with increasing reclaim rubber content. The reason for higher $100 \%$ and $200 \%$ moduli may be due to higher crosslink density (Figure 2) of the vulcanizates, arising out of the gel present in reclaim rubber or may be due to the presence of active functional sites in reclaim rubber which may participate in crosslinking during the process of vulcanization. As crosslink density of the vulcanizates increases with increasing reclaim rubber content, chain mobility decreases and more load is required for $100 \%$ and $200 \%$ elongation. The increasing value of tensile strength with reclaim rubber content is probably due to the presence of carbon black left in the reclaim rubber [12]. It is known [7,21,22] that the partial devulcanization of ground rubber tire (GRT) facilitates the interface adhesion between the surface chains of reclaim rubber (RR) particles and surrounding rubber matrix due to their co-crosslinking in the interphase layer. The increase in the value of elongation at break with reclaim rubber content can indicate a better compatibility in interphase layer of the rubber matrix and reclaimed rubber particles $[23,24]$. The growth of the values of hardness observed at increasing RR content in SBR/RR (re)vulcanizates obviously evidences of more intensive post vulcanization process in the blends due to presence of additional sulfur released at the devulcanization of GRT [15].

Effect of carbon black loading was studied in SBR/RR $(80 / 20)$ blend system. It is seen that with increase in carbon black loading $100 \%$ and $200 \%$ moduli, tensile strength increases. This can be explained by corresponding increase in crosslinking value data. The higher crosslinking value of the vulcanizates is conclusive evidence

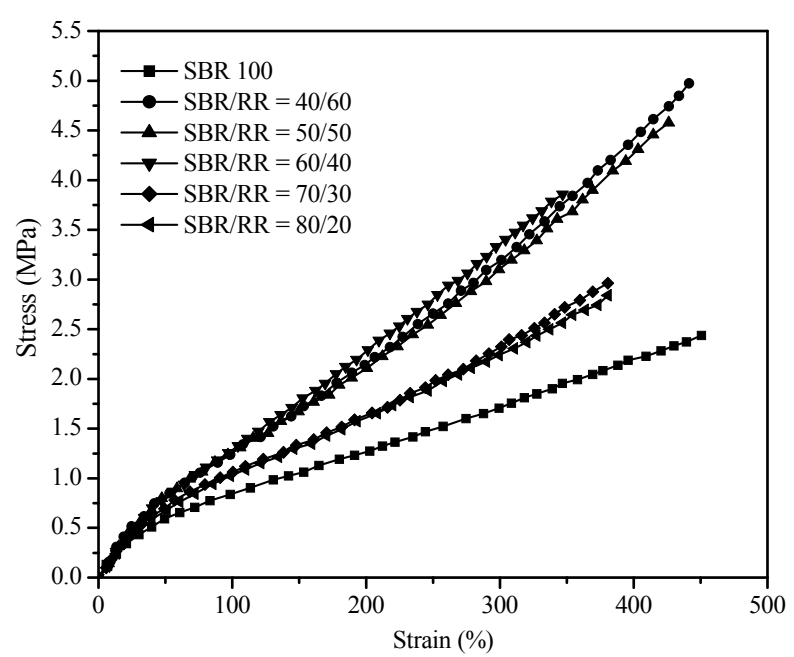

Figure 1. Stress - Strain behavior of SBR/RR blend system.

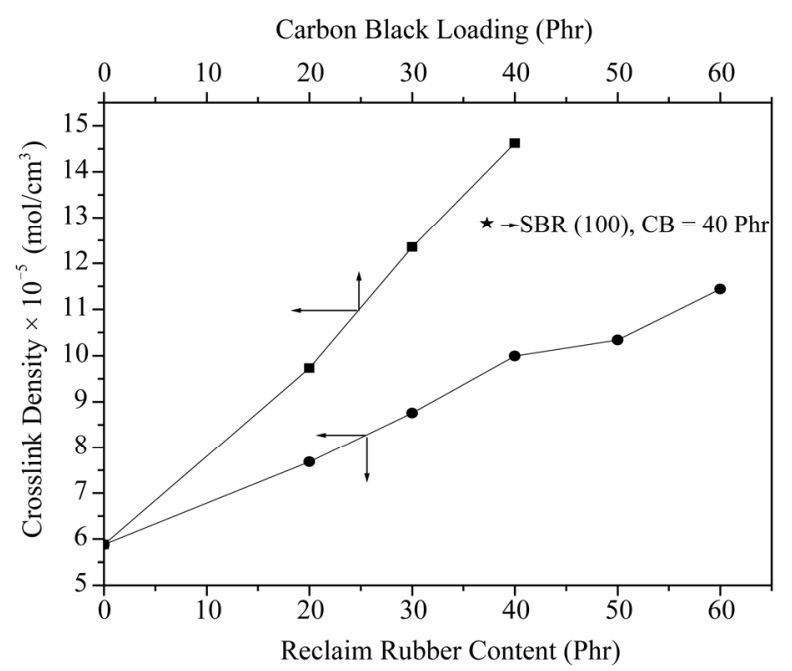

Figure 2. Crosslink density of SBR/RR blend system as a function of reclaim rubber content and carbon black loading.

for the presence of a network with a greater number of filler polymer interactions, constraining molecular mobility in the polymer. The tensile strength of $40 \mathrm{phr}$ carbon black loaded SBR/RR (80/20) vulcanizate is higher compared to that of the control formulation 7 i.e. vulcanizate containing no reclaim rubber. Elongation at break decreases with increasing carbon black loading. Hardness increases because with increasing carbon black loading vulcanizates become stiff and hard. The increase in the value of Mooney viscosity with carbon black loading further indicates that the processing of the rubber compound become difficult if higher amount of carbon black is incorporated into the rubber matrix.

\subsection{Effect of Thermal Aging}

The aging characteristics of SBR/RR vulcanizates should 
be given proper attention because reclaim rubber itself is a degraded mass. Thus accelerated aging test were performed for SBR/RR vulcanizates. Percent retention of $100 \%$ and 200\% modulus are shown in Figures 3 and 4. In all the cases it was observed that percent retention of $100 \%$ and $200 \%$ modulus increases with increasing reclaim rubber content and with progress of aging. This may be due to residual crosslinking during progress of aging which is further enhanced due to the presence of reclaim rubber, containing active functional sites. Percent retention of tensile strength is shown in Figure 5. From the figure it is evident that percent retention of tensile strength decreases with progress of aging but increases with increasing reclaim rubber content at a particular time of aging. This may be due to increasing crosslink density of the vulcanizates with progress of aging. The percent retention of elongation at break for the various SBR/RR systems at different RR content after aging is shown in Figure 6. But percent retention of elongation at break values at higher reclaim content such as 50 and 60 $\mathrm{wt} \%$ reduces considerably; this is a result of both thermooxidative degradation and post vulcanization of SBR/RR (re)vulcanizates studied. Percent retention of hardness is shown in Figure 7. With progress of aging as the vulcanizates become stiff therefore hardness increases.

Effect of carbon black loading on \% retention of properties after $72 \mathrm{~h}$ aged SBR/RR (80/20) blend system was shown in Figure 8. The percent retention value of both $100 \%$ and $200 \%$ modulus continuously increases with increasing carbon black loading. But the percent retention values of tensile strength and elongation at break shows a different behavior. Both the properties shows maximum percent retention values for $20 \mathrm{phr}$ carbon black loading compared to that of the control formulation.

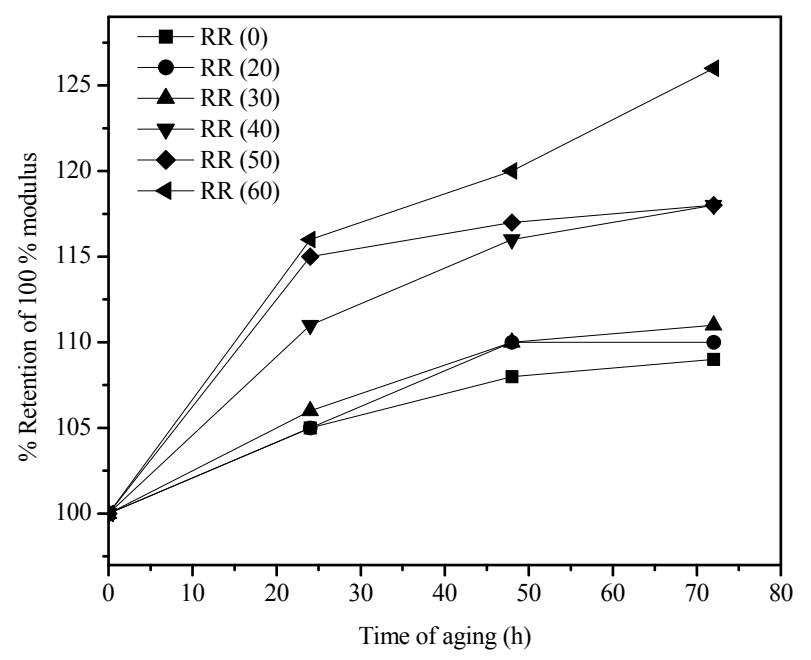

Figure 3. Effect of reclaim rubber content on \% retention of $100 \%$ Modulus.

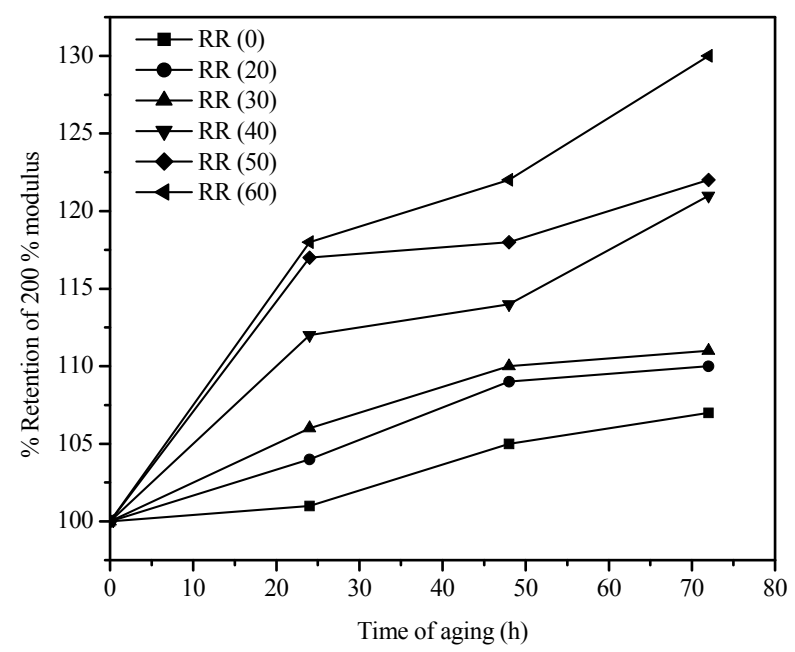

Figure 4. Effect of reclaim rubber content on \% retention of $200 \%$ Modulus.

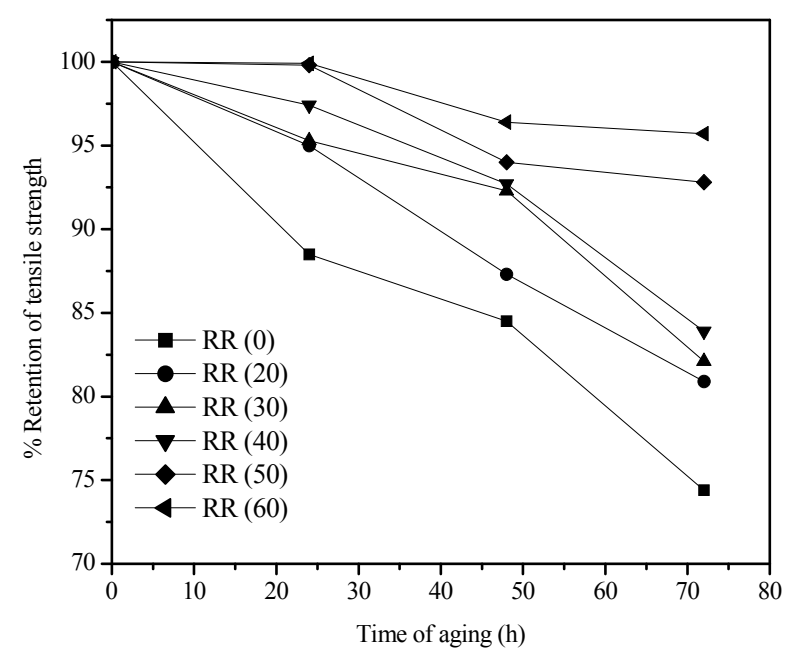

Figure 5. Effect of reclaim rubber content on \% retention of Tensile Strength.

However, for 30 and $40 \mathrm{phr}$ carbon black loading the percent retention values considerably decreases due to aging. Although the percent retention of tensile strength for 30 and $40 \mathrm{phr}$ carbon black loading is not less than that of the control formulation. It is seen from Figure 8 that percent retention of hardness was almost constant with increasing carbon black loading. These results show the effectiveness of $20 \mathrm{phr}$ carbon black in the SBR/RR $(80 / 20)$ blend system. Thus the aging performances of formulation containing reclaim rubber are superior than that of the control formulation which does not contain any reclaim rubber. This phenomenon indicates the antiaging characteristics of reclaim rubber.

\subsection{Thermogravimetric Analysis}

Thermal degradation of different SBR/RR vulcanizates 


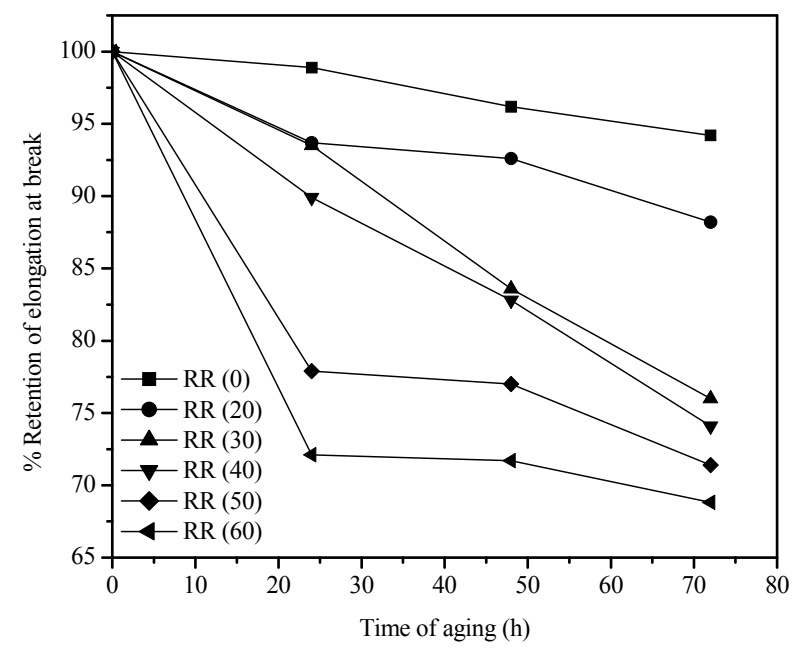

Figure 6. Effect of reclaim rubber content on \% retention of Elongation at Break.

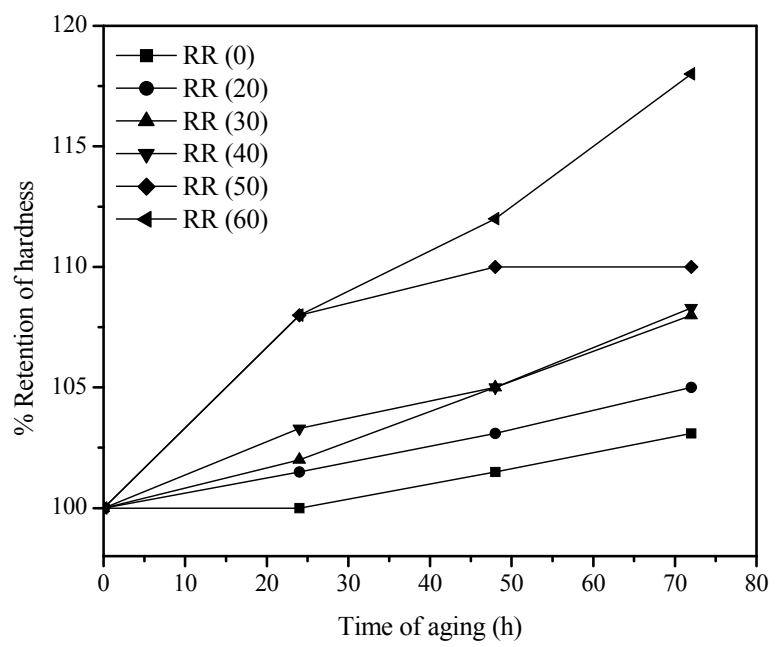

Figure 7. Effect of reclaim rubber content on \% retention of Hardness.

in inert atmosphere was analyzed and corresponding results are given in Figure 9. The thermogravimetric analysis were performed in nitrogen atmosphere, which shows only thermal degradation behavior compare to the combine effect of thermal as well as termooxidative degradation in presence of oxygen or air. The tempera- ture interval of degradation stages evaluated from DTG curves, temperature of the stages maximum rate of degradation, sample weight loss at the temperatures and char residue values are listed in Table 2 . All SBR/RR blend system shows two characteristic degradation peak in DTG curve between $320^{\circ} \mathrm{C}-530^{\circ} \mathrm{C}$ (Figure 9). But for all the vulcanizates initial weight loss occurs between $50-300^{\circ} \mathrm{C}$. Pure SBR shows 3.6\% wt loss up to $300^{\circ} \mathrm{C}$ whereas with increase in reclaim rubber content it goes up to $10 \%$ for $\mathrm{SBR} / \mathrm{RR}$ blend system. This initial weight loss under $\mathrm{N}_{2}$

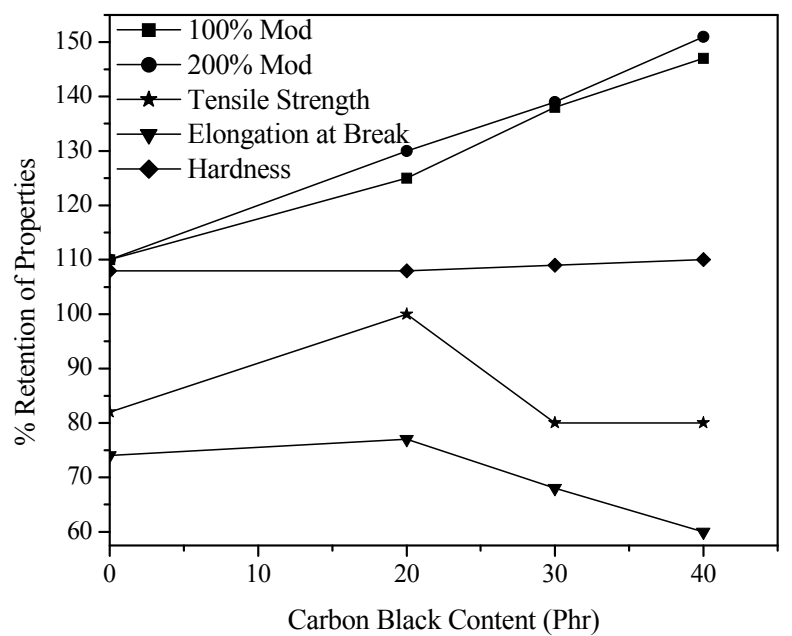

Figure 8. Effect of carbon black loading on \% Retention of properties after $72 \mathrm{~h}$ aged SBR/RR (80/20) blend system.

atmosphere between $50^{\circ} \mathrm{C}-300^{\circ} \mathrm{C}$ is due to the volatilization of processing oil or any other low boiling point component present in pure and blend system. As reclaim rubber contain large amount of processing additives compare to virgin rubber, so with increasing reclaim rubber content initial weight loss increases from $3.6 \%$ to $10 \%$.

As RR contain some NR for that reason SBR/RR blend shows two distinct peak in DTG curve which was also observed for NR/SBR blend system [25]. Pure SBR shows $10.57 \%$ wt loss in $1^{\text {st }}$ degradation step. With increase in reclaim rubber content $\%$ wt loss in $1^{\text {st }}$ degradation step gradually increases and maximum $24.13 \%$ was observed at 40phr SBR containing SBR/RR blend system. $1^{\text {st }}$ degradation was faster with increase in RR content in $\mathrm{SBR} / \mathrm{RR}$ blend system. Low temperature degradation was much pronounced with increase in RR content in $\mathrm{SBR} / \mathrm{RR}$ blend system. If we compare our TGA results with pure RR system, it was observed that reclaim rubber shows three steps degradation. Out of three steps, $2^{\text {nd }}$ degradation step occurs in between $334.4^{\circ} \mathrm{C}-507.5^{\circ} \mathrm{C}$. Actually $2^{\text {nd }}$ degradation step of pure reclaim rubber partially merge with the $1^{\text {st }}$ degradation step of SBR/RR blend system. As a result of which \% wt loss increases in $1^{\text {st }}$ degradation step of SBR/RR blend system with increase in reclaim rubber content.

But in case of second degradation the complete opposite train was observed. Pure SBR shows around $80 \%$ weight loss in second degradation step. This is the characteristic degradation peak for pure SBR in thermo-gravimetric analysis. The \% wt. loss of blend vulcanizates is decreased in $2^{\text {nd }}$ degradation step with increase in reclaim rubber content. This may be due to the low SBR content in SBR/RR blend system. The same reason was also ap- 


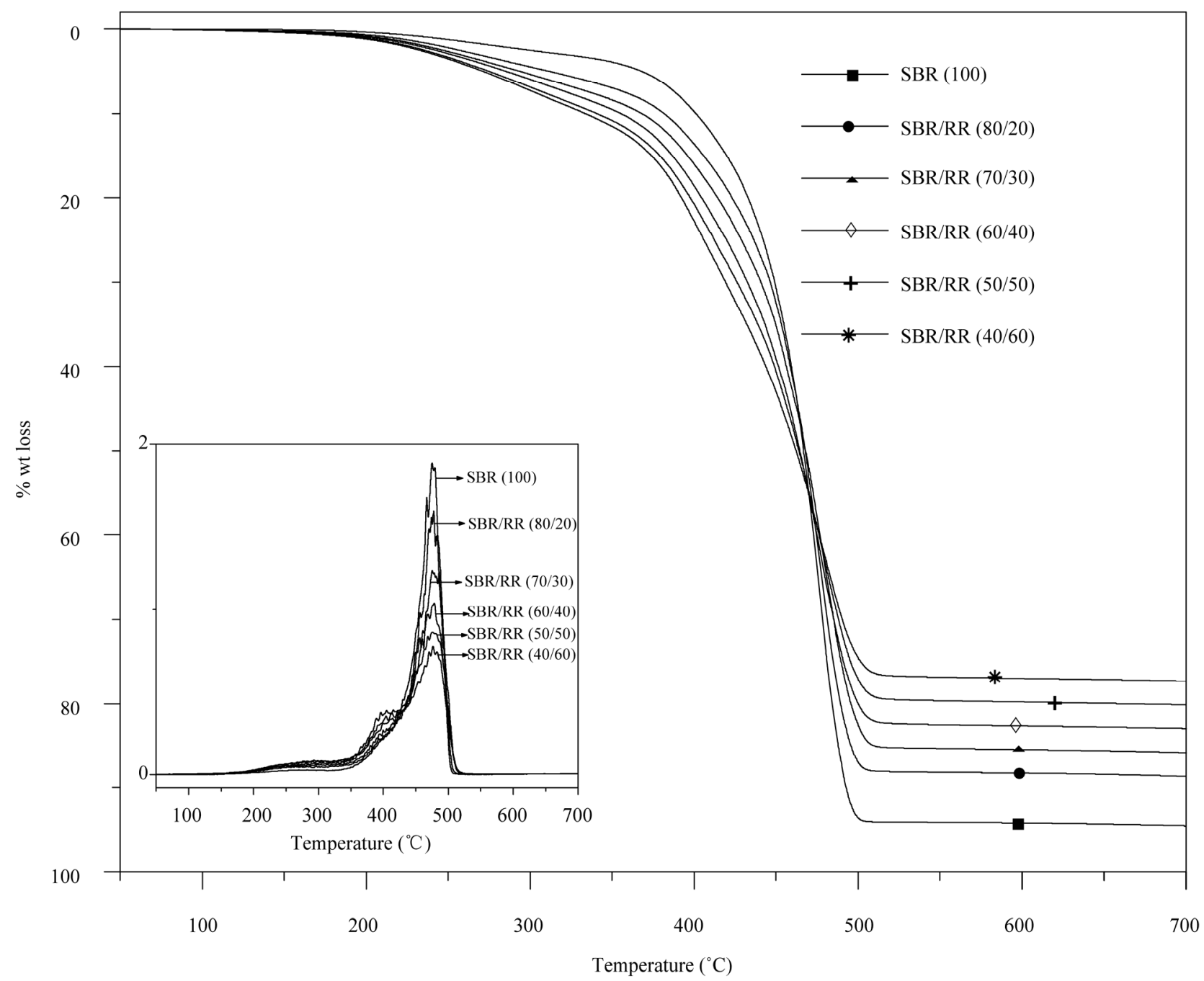

Figure 9. Thermogravimetric analysis of SBR/RR Vulcanizates.

Table 2. Degradation temperature and \% weight loss of SBR/RR vulcanizates.

\begin{tabular}{|c|c|c|c|c|c|c|c|c|c|c|c|c|c|c|c|}
\hline \multirow{2}{*}{\multicolumn{2}{|c|}{ Blend }} & \multirow{2}{*}{\multicolumn{3}{|c|}{ Initial wt. Loss }} & \multicolumn{5}{|c|}{$1^{\text {st }}$ degradation } & \multicolumn{5}{|c|}{$2^{\text {nd }}$ degradation } & \multirow{2}{*}{$\%$ residue } \\
\hline & & & & & Start & Peak & End & $\%$ w & t loss & Sta & & Peak & End & $\%$ wt loss & \\
\hline \multicolumn{3}{|c|}{ SBR (100) } & \multicolumn{2}{|l|}{3.66} & 343.53 & 395.44 & 417.12 & & .57 & \multicolumn{2}{|c|}{417.12} & 476.85 & 512.75 & 79.83 & 5.384 \\
\hline \multicolumn{3}{|c|}{ SBR/RR $(80 / 20)$} & \multicolumn{2}{|l|}{6.76} & 346.38 & 395.44 & 418.90 & & .83 & \multicolumn{2}{|c|}{418.90} & 476.85 & 514.18 & 69.49 & 11.195 \\
\hline \multicolumn{3}{|c|}{ SBR/RR (70/30) } & \multicolumn{2}{|c|}{7.77} & 340.69 & 395.44 & 423.17 & & .16 & \multicolumn{2}{|c|}{423.17} & 479.69 & 512.64 & 62.35 & 14.045 \\
\hline \multicolumn{3}{|c|}{ SBR/RR (60/40) } & \multicolumn{2}{|l|}{8.77} & 340.69 & 388.33 & 421.75 & & .98 & \multicolumn{2}{|c|}{421.75} & 476.85 & 512.64 & 56.62 & 16.945 \\
\hline \multicolumn{3}{|c|}{ SBR/RR $(50 / 50)$} & \multicolumn{2}{|c|}{10.00} & 340.69 & 398.29 & 431.70 & & .08 & \multicolumn{2}{|c|}{431.70} & 476.85 & 523.07 & 47.42 & 19.784 \\
\hline \multicolumn{3}{|c|}{ SBR/RR (40/60) } & \multicolumn{2}{|c|}{9.63} & 328.96 & 394.02 & 428.86 & & .13 & \multicolumn{2}{|c|}{428.86} & 478.27 & 531.59 & 43.01 & 22.607 \\
\hline \multicolumn{3}{|c|}{ Initial wt. } & \multicolumn{3}{|c|}{$1^{\text {st }}$ degradation } & \multicolumn{4}{|c|}{$2^{\text {nd }}$ degradation } & \multicolumn{5}{|c|}{$3^{\text {rd }}$ degradation } & \\
\hline \multirow[t]{2}{*}{ RR } & Loss & Start & Peak & End & $\%$ wt Loss & Start & Peak & End & $\% \mathrm{wt}$ & Loss & Start & Peak & End & $\%$ wt Loss & 9.81 \\
\hline & 15.00 & 160 & 274 & 336 & 13.28 & 336 & 400 & 507 & 49 & & 507 & 566 & 671 & 25.79 & \\
\hline
\end{tabular}


plicable for $2^{\text {nd }}$ degradation step in blend system which shows less \% wt loss with increase in RR content. This is due to the fact that the $3^{\text {rd }}$ degradation step of pure reclaim rubber affects the $2^{\text {nd }}$ degradation step of SBR/RR blend system. The lower \% wt loss in the second step is due to both the higher carbon black content and to the greater $\% \mathrm{wt}$ loss of the first step.

\subsection{SEM Study}

Scanning electron micrograph of the tensile fractured surface of fresh SBR and different SBR/RR vulcanizates are displayed in Figure 10. The micrograph of fresh SBR vulcanizate showed homogeneous surface morphology. Whereas in the reclaim rubber containing vulcanizates several number of crack paths in different directions was observed which is making the vulcanizate susceptible under mechanical stress. Here in case of reclaim rubber containing vulcanizate, the fracture mode showed the

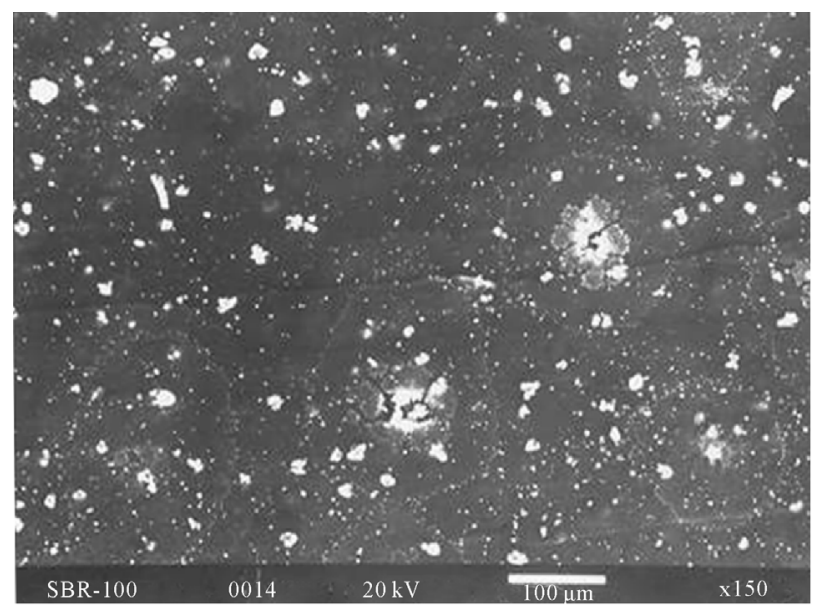

(a)

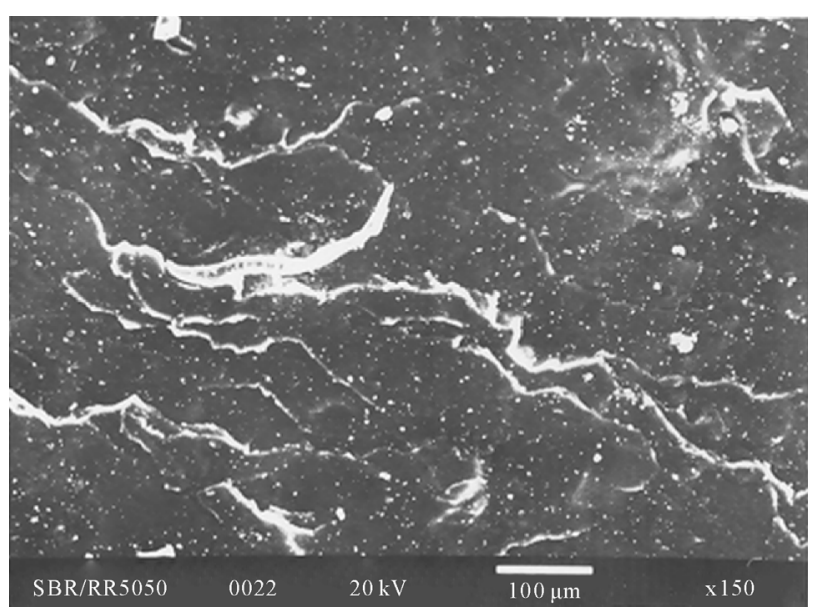

(c) failure mode that was less rubbery in nature, due to higher cross link density of the vulcanizate.

\section{Conclusions}

Mechanochemical reclaiming of GRT was carried out by multifunctional reclaiming agent, TMTD. The reclaimed rubber prepared in this investigation, when mixed with fresh SBR has been found to increase the tensile strength by about $19 \%$ for $20 \%$ reclaim containing vulcanizate and $115 \%$ for $60 \%$ reclaim containing vulcanizates. It is observed that the aging characteristics of the reclaim rubber containing vulcanizates are superior compared to that of the control formulation, which does not contain any reclaim rubber. TGA shows that the thermal stability of the vulcanizate increases with increasing reclaim rubber proportion. SEM studies indicate that reclaim rubber containing vulcanizates are vulnerable under mechanical stress. Another advantage of this reclaiming agent is the

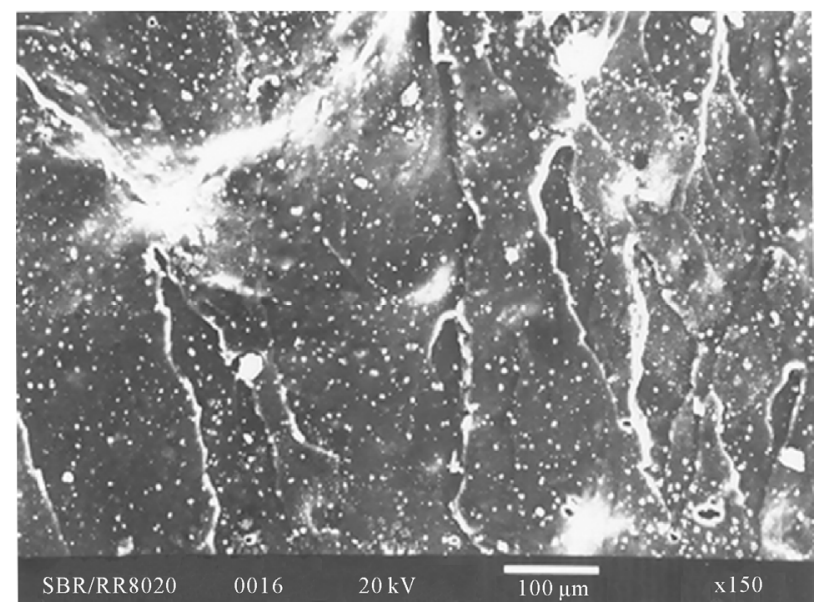

(b)

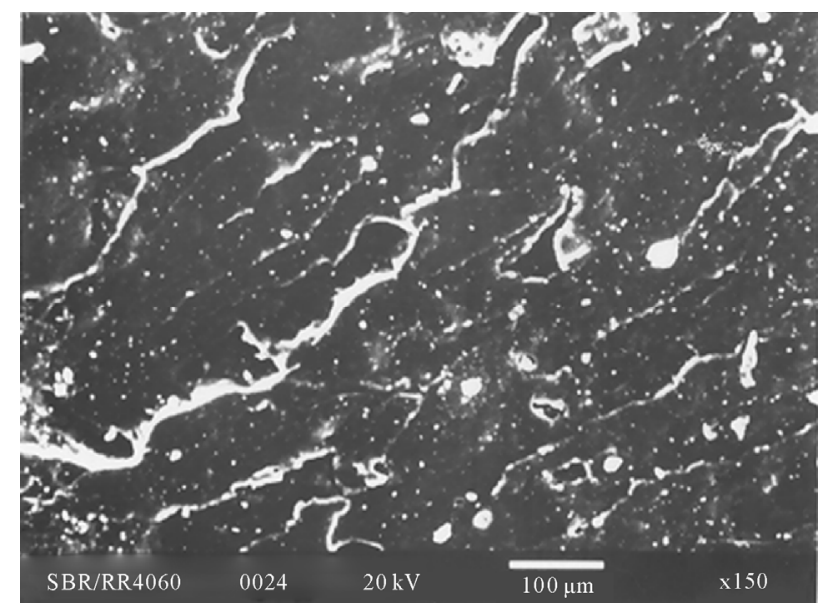

(d)

Figure 10. Tensile fractured surface of (a) SBR (100) (b) SBR/RR (80/20) (c) SBR/RR (50/50) and (d) SBR/RR (40/60) blend system. 
reduced smell during the reclamation process and of the final reclaims, one of the most important short comings of other disulfides used for this purpose.

\section{Acknowledgements}

The authors, Debapriya De thankfully acknowledge the financial support by the Department of Science and Technology (DST), New Delhi, India for carrying out the present research work.

\section{REFERENCES}

[1] F. G. Smith, "Rubber ACS Division," Meeting, IRC, Orlando, 26-28 October 1993.

[2] H. F. Mark, N. M. Bikales, C. G. Overberger and G. Menges, "Encyclopedia of Polymer Science and Engineering," Vol. 14, Wiley, New York, 1988, pp. 787-804.

[3] A. A. Merchant and M. A. Petrich, "Pyrolysis of Scrap Tires and Conversion of Chars to Activated Carbon," AIChE Journal, Vol. 39, No. 8, 1993, pp. 1370-1376. doi:10.1002/aic.690390814

[4] J. P. Lin, C. Y. Chang and C. H. Wu, "Pyrolytic Treatment of Rubber Waste: Pyrolysis Kinetics of Styrene-Butadiene Rubber," Journal of Chemical Technology \& Biotechnology, Vol. 66, No. 1, 1996, pp. 7-14. doi:10.1002/(SICI)1097-4660(199605)66:1<7::AID-JCT B474>3.0.CO;2-I

[5] I. A. Hussein, H. I. A. Wahhab and M. H. Iqbal, "Influence of Polymer Type and Structure on Polymer Modified Asphalt Concrete Mix," The Canadian Journal of Chemical Engineering, Vol. 84, No. 4, 2006, pp. 480487. doi:10.1002/cjce.5450840409

[6] G. S. Miguel, G. D. Fowler, M. Dall'Orso and C. J. Sollars, "Porosity and Surface Characteristics of Activated Carbons Produced from Waste Tyre Rubber," Journal of Chemical Technology \& Biotechnology, Vol. 77, No. 1, 2002, pp 1-8. doi:10.1002/jctb.518

[7] B. Adhikari, D. De and S. Maiti, "Reclaim and Recycle of Waste Rubber," Progress in Polymer Science, Vol. 25, No. 7, September 2000, pp. 909-948. doi:10.1016/S0079-6700(00)00020-4

[8] D. De, A. Das, D. De, B. Dey, S. C. Debnath and B. C. Roy, "Reclaiming of Ground Rubber Tire (GRT) by a Novel Reclaiming Agent," European Polymer Journal, Vol. 42, No. 4, April 2006, pp. 917-927. doi:10.1016/j.eurpolymj.2005.10.003

[9] D. De, D. De and G. M. Singharoy, "Reclaiming of Ground Rubber Tire (GRT) by a Novel Reclaiming Agent: Part 1: Virgin Natural Rubber (NR)/Reclaimed GRT Vulcanizates," Polymer Engineering Science, Vol. 47, No. 7, 2007, pp. 1091-1100. doi:10.1002/pen.20790

[10] V. V. Rajan, W. K. Dierker, R. Joseph and J. W. M. Noordermeer, "Effect of Diphenyl Disulfides with Different Substituents on the Reclamation of NR Based Latex Products," Journal of Applied Polymer Science, Vol. 104, No. 6, June 2007, pp. 3562-3580. doi:10.1002/app.25925
[11] N. Sombatsompop and C. Kumnuantip, "Rheology, Cure Characteristics, Physical and Mechanical Properties of Tire Tread Reclaimed Rubber/Natural Rubber Compounds," Journal of Applied Polymer Science, Vol. 87, No. 10, 2003, pp. 1723-1731. doi:10.1002/app.11698

[12] C. Kumnuantip and N. Sombatsompop, "Dynamic Mechanical Properties and swelling behavior of NR/reclaimed rubber blends," Materials Letter, Vol. 57, No. 21, 2003, pp. 3167-3174. doi:10.1016/S0167-577X(03)00019-3

[13] T. D. Sreeja and S. K. N. Kutty, "Cure Characteristics and Mechanical Properties of Natural Rubber/Reclaimed Rubber Blends," Polymer Plastic Technology Engineering, Vol. 39, No. 3, 2000, pp. 501-512. doi:10.1081/PPT-100100043

[14] D. De, B. Adhikari and S. Maiti, "Reclaiming of Rubber by a Renewable Resource Material, Part 4, Assessment of Vulcanized SBR Reclaiming Process," Kautschuk Gummi Kunststoffe, Vol. 53, No. 6, 2000, pp. 346-351.

[15] D. De, B. Adhikari and S. Maiti, "Reclaiming of Rubber by a Renewable Resource Material, Part 1, Reclaiming of Natural Rubber Vulcanizates," Journal of Polymer Materials, Vol. 14, 1997, pp. 333-341.

[16] D. De, B. Adhikari and S. Maiti, "Reclaiming of Rubber by a Renewable Resource Material, Part 2, Comparative Evaluation of Reclaiming Process of NR Vulcanizate by RRM and Diallyl disulfide," Journal of Applied Polymer Science, Vol. 73, No. 14, 1999, pp. 2951-2958. doi:10.1002/(SICI)1097-4628(19990929)73:14<2951::AI D-APP19>3.3.CO;2-2

[17] P. Nevatia, T. S. Banerjee, B. Dutta, A. Jha, A. K. Naskar and A. K. Bhowmick, "Thermoplastic Elastomers from Reclaimed Rubber and Waste Plastics," Journal of Applied Polymer Science, Vol. 83, No. 9, 2002, pp. 20352042. doi:10.1002/app.10115

[18] C. R. Parks and R. J. Brown, "Crosslink Density of Elastomers. A New Gas-Chromatographic Method," Rubber Chemistry and Technology, Vol. 49, No. 2, 1976, pp. 233- 236. doi: $10.5254 / 1.3534960$

[19] P. J. Flory and J. Rehner, "Statistical Mechanics of Cross-Linked Polymer Networks II. Swelling," Journal of Chemical Physics, Vol. 11, No. 2, 1943, pp. 521-526. doi:10.1063/1.1723792

[20] D. De, B. Adhikari and S. Maiti, "Reclaiming of Rubber by a Renewable Resource Material, Part 3, Evaluation of properties of NR reclaim," Journal of Applied Polymer Science, Vol. 75, No. 12, 2000, pp. 1493-1502. doi:10.1002/(SICI)1097-4628(20000321)75:12<1493::AI D-APP8>3.3.CO;2-L

[21] V. M. Makarov and V. F. Drozdovski, "Re-use of the Amortized Trunks and Waste of Rubber Products Manufacture," Chemistry, Leningard, 1986.

[22] V. M. Makarov and V. F. Drozdovski, "Reprocessing of Tires and Rubber Waste," Ellis Horwood, New York, 1995.

[23] J. R. M. Duhaime and W. E. Baker, "The Influence of Particle Size on Composite Properties and the Effective- 
ness of a Reactive blending of Polyethylene and Scrap Rubber," Plastic Rubber and Composites Processing and Applications, Vol. 15, No. 2, 1991, pp. 87-93.

[24] B. E. Corley and H. J. Radusch, "Intensification of Interfacial Interaction in Dynamic Vulcanization," Journal of Macromolecular Science-Physics, Vol. B37, No. 2, 1998, pp. 265-273. doi:10.1080/00222349808220471

[25] M. J. Fernandez-Berridi, N. Gonzalez, A. Mugica and C. Bernicot, "Pyrolysis-FTIR and TGA Techniques as Tools in the Characterization of Blends of Natural Rubber and SBR," Thermochemica Acta, Vol. 444, No. 1, 2006, pp. 65-70. doi:10.1016/j.tca.2006.02.027 